\title{
EFFECTS OF THE ALLOYING ELEMENTS ON THE THERMAL EXPANSION COEFFICIENTS OF NONMAGNETIC NI-BASE ALLOYS AND AUSTENITIC STEELS
}

\author{
S. K. Hwang, F. C. Hull and J. M. Wells \\ Metallurgy Department \\ Westinghouse Elec. Corp. R\&D Center \\ Pittsburgh, Pennsylvania 15235
}

\begin{abstract}
Summary
A regression model to predict the thermal expansion coefficient (averaged from room tempcrature to $538^{\circ} \mathrm{C}$ ) of nonmagnetic nickel-base alloys and austenitic steels was obtained. The thermal expansion values used in the regression modelling were taken from published data bases of commercial alloys. An experimental verification of the model was also conducted on 23 nickel-base laboratory heats of varying chemical compositions: 19 solid solution alloys and 4 precipitation-hardened alloys. The experimental results confirmed the effects of the alloying elements as predicted by the regression model: $\mathrm{Mn}, \mathrm{Fe}$ and $\mathrm{Cr}$ increased the thermal expansion coefficient of alloys whereas $\mathrm{Mo}, \mathrm{W}, \mathrm{C}, \mathrm{Al}$, $\mathrm{Ti}$ and $(\mathrm{Nb}+\mathrm{Ta})$ decreased it. The effects of $\mathrm{Mo}, \mathrm{Al}$ and $\mathrm{Ti}$ agreed with the results of prior experimental work on similar alloys. A preliminary evaluation of the resistance to SCC (Stress Corrosion Cracking) of the experimental alloys showed that the solid solution alloys had a good resistance in boiling $\mathrm{MgCl}_{2}$ solution and in pressurized, hot $\mathrm{NaOH}$ solution, whereas the precipitation-hardened alloys had a comparatively low SCC-resistance in the $\mathrm{NaOH}$ solution.
\end{abstract}




\section{Introduction}

The thermal expansion of metal alloys has a significant influence on the performance of components which are subject to temperature differentials. The significance multiplies for assembled or welded components of unmatched thermal expansion coefficients $(\alpha)$ in steam turbines or gas turbines. Despite the pragmatic significance of thermal expansion, there are few published papers on the relationship between $\alpha$ and alloy composition. In an alloy system where the Curie-temperaturerelated anomaly is observed, Muzyka et al. ${ }^{1,2}$ made a systematic attempt to obtain a low $\alpha$ in high nickel precipitation-hardened alloys by controlling the chemical composition. The resultant $\mathrm{Fe}-\mathrm{Ni}-\mathrm{Co}$ alloys (magnetic) retained the $\alpha$ of approximately half of that of typical nickel-base superalloys in the temperature range of RT- $650^{\circ} \mathrm{C}$. In nonmagnetic nickel-base alloys, Morrow et al. ${ }^{3}$ experimentally evaluated the role of alloying elements on the $\alpha$. They found that Mo, Ti and Al lowered the $\alpha$ : Mo in solid-solution alloys as well as in precipitation-hardened alloys, and $\mathrm{Al}$ and $\mathrm{Ti}$ in precipitation-hardened alloys. The present work was aimed at developing a regression model to predict the $\alpha$ 's of nonmagnetic nickel-base alloys and austenitic steels of a broad range of chemical compositions, and verifying the model experimentally in nickel-base alloys of selected compositions. Also, a preliminary evaluation of the experimental alloys was performed in environments conducive to SCC.

\section{The Regression Model for the Mean Thermal Expansion Coefficient}

$$
\text { Data on the } \alpha_{538^{\circ} \mathrm{C}} \text { (the mean thermal expansion coefficient from room }
$$

temperature to $538^{\circ} \mathrm{C}$ ) of a total of 216 commercial high-Ni alloys of mainly $\gamma$ phase were compiled from Alloy Digest, technical handbooks and manufacturers' publications, such as International Nickel Co. publications and a Haynes Stellite handbook. We included iron-, nickel- and cobalt-base alloys, usually with some level of $\mathrm{Cr}$, but in any event sufficiently alloyed that the Curie temperature was below room temperature. This was to ensure that the effects of magnetic interactions on $\alpha$ did not introduce an additional variable. No distinction was made between wrought and cast alloys. The precipitation-hardenable alloys were assumed to be in the aged condition. The chemical composition data were essentially based on the nominal composition except when analysis results were available. When the range rather than the nominal value was given, the median value of the range was used. Frequently, the amounts of $\mathrm{Nb}$ and $\mathrm{Ta}$ were specified as one total value, thercforc, were treated as a sum of $(\mathrm{Nb}+\mathrm{Ta})$ in the regression analysis. Data on $\alpha$ sometimes showed $0^{\circ} \mathrm{C}$ instead of room temperature as the reference temperature. However, no attempt was made to adjust the data accordingly, and room temperature was assumed as the reference temperature for all $\alpha$ data.

In the regression model it was assumed that the effects of composition on $\alpha$ could be represented by an equation, e.g. :

$$
\alpha=\beta_{\mathrm{o}}+\beta_{1} \mathrm{~A}+\beta_{2} \mathrm{~A}^{2}+\beta_{3} \mathrm{~B}+\beta_{4} \mathrm{~B}^{2}+\beta_{5} \mathrm{AB}+\beta_{6} \mathrm{C}+\ldots \ldots
$$

where $\beta_{\mathrm{o}}, \beta_{1}, \beta_{2}, \ldots$ are the regression coefficients and $\mathrm{A}, \mathrm{B}, \mathrm{C} \ldots$ represent the amount of various alloying elements. Linear regression analysis, based on the method of the least squares, was used to determine the regression coefficients. 
The detailed results of the regression analysis are presented in Table I, which can be summarized as follows:

$$
\begin{aligned}
& \alpha_{538^{\circ} \mathrm{C}}\left(10^{-6} /{ }^{\circ} \mathrm{C}\right)=14.378+0.0123 \mathrm{Co}+0.0284 \mathrm{Cr}-0.1012 \mathrm{Mo}-0.0520 \mathrm{~W}+ \\
& 0.0277 \mathrm{Fe}-0.1280 \mathrm{Ti}-0.0214 \mathrm{Al}-0.0165(\mathrm{Nb}+\mathrm{Ta})+0.0841 \mathrm{Mn}-1.5336 \mathrm{C}-0.0005103 \\
& \mathrm{Cr}^{2}+0.0003553 \mathrm{Fe}^{2}-0.0006674 \mathrm{Mn}^{2}+0.0011232 \mathrm{CoFe}+0.0018072 \mathrm{MoFe}
\end{aligned}
$$

where the unit for the elements is weight percent. The model has several second order terms: $\mathrm{Cr}^{2}, \mathrm{Fe}^{2}, \mathrm{Mn}^{2}$, CoFe and MoFe. These were selected from the list of possible second order combinations. The selection criterion was the statistical significance which was determined by comparing the F-ratio and the magnitude of the standard error of the coefficients.

\section{Table I.}

\begin{tabular}{|c|c|c|c|}
\hline Term & Coefficient & $\begin{array}{l}\text { Standard Error } \\
\text { of Coefficient }\end{array}$ & F-Ratic \\
\hline Constant & 14.378 & 0.18 & -- \\
\hline Co & 0.0123 & 0.0045 & 7.8 \\
\hline $\mathrm{Cr}$ & 0.0284 & 0.0149 & 3.6 \\
\hline Mo & -0.1012 & 0.0076 & 183 \\
\hline W & -0.0520 & 0.0155 & 11.3 \\
\hline $\mathrm{Fe}$ & 0.0277 & 0.0074 & 14.1 \\
\hline $\mathrm{Ti}$ & -0.1280 & 0.0360 & 12.2 \\
\hline & -0.0214 & 0.0306 & 0.5 \\
\hline $\mathrm{Nb}+\mathrm{Ta}$ & -0.0165 & 0.0306 & 0.3 \\
\hline Mn & 0.0841 & 0.0176 & 22.7 \\
\hline $\mathrm{C}$ & -1.5336 & 0.2880 & 26.9 \\
\hline $\mathrm{Cr}^{2}$ & -0.0005103 & 0.0003780 & 1.8 \\
\hline $\mathrm{Fe}^{2}$ & 0.0003553 & 0.0000972 & 13.2 \\
\hline $\mathrm{Mn}^{2}$ & -0.0006674 & 0.0001638 & 16.6 \\
\hline $\mathrm{CoFe}$ & 0.0011232 & 0.0003960 & 8.0 \\
\hline MoFe & 0.0018072 & 0.0006120 & 8.9 \\
\hline & $\begin{array}{l}\text { io of Regres } \\
\text { ard Error } \\
\text { icient of De }\end{array}$ & \multicolumn{2}{|c|}{$\begin{array}{l}245 \\
0.468 \\
0.95\end{array}$} \\
\hline
\end{tabular}

Results of the linear regression on the effects of the alloying elements on $\alpha_{538^{\circ} \mathrm{C}}$ of nonmagnetic Ni-base alloys and austenitic steels.

It is noted that most solid-solution alloying elements except Mo and $\mathbf{W}$ increase $\alpha$, while the elements which induce precipitation decrease $\alpha$. Molybdenum and tungsten showed the strong effects of decreasing $\alpha$. The absolute magnitude of the coefficient of carbon is the highest of all; however, the effect is usually mitigated by the small quantity 
of carbon usually present as an alloying element.

\section{Experimental Verification of the Regression Model}

The chemical compositions of experimental heats were selected in such a way that $\alpha$ would be relatively low and the SCC-resistance high. The combination of the two properties are required often in power generation equipment ${ }^{4-5}$, e.g., SCC-resistant fasteners in contact with low expansion ferritic alloy components, or the transition joint weldment between the high expansion austenitic alloy and the ferritic steel. While Fe and $\mathrm{Cr}$ increase $\alpha$ as shown in Eq. (2), Ni promotes the SCC-resistance. Mo addition was critical because of its strong effect of decreasing $\alpha$; however, it is known that, in excessive amounts, Mo could cause embrittlement by forming undesirable phases. Considering these factors we determined the pivotal composition as $15 \% \mathrm{Cr}, 2.5 \% \mathrm{Mo}$, $10 \% \mathrm{Fe}$ and balance $\mathrm{Ni}$, and varied the ranges of the elements as $\mathrm{Cr}: 12-21 \%, \mathrm{Mo}: 0-5$ $\%$ and Fe: 4-16\%. A total of 19 variations of solid solution alloys and 4 variations of precipitation-hardened alloys, as shown in Table II, were selected for the measurement of $\alpha$. The pattern of elemental combinations in the table constitutes what is called a central composite design, a limited scale factorial design. The factorial design gives better estimates of the elemental effects with fixed variance than the single factor approach.

Table II.

Nominal chemical compositions (in wt.\%) of the alloys used in the experiment.

\begin{tabular}{|c|c|c|c|c|c|c|c|c|c|c|c|c|}
\hline No. & $\mathrm{Ni}$ & Co & $\mathrm{Cr}$ & Mo & $\underline{W}$ & $\underline{\mathrm{Fe}}$ & $\mathrm{Ti}$ & Al & $\mathrm{Nb}$ & $\mathrm{Mn}$ & Si & $\mathrm{C}$ \\
\hline 1 & 80.2 & 0 & 12 & 0 & 0 & 7 & 0 & 0 & 0 & .5 & .25 & .03 \\
\hline 2 & 74.2 & 0 & 12 & 0 & 0 & 13 & 0 & 0 & 0 & .5 & .25 & .03 \\
\hline 3 & 74.2 & 0 & 18 & 0 & 0 & 7 & 0 & 0 & 0 & .5 & .25 & .03 \\
\hline 4 & 68.2 & 0 & 18 & 0 & 0 & 13 & 0 & 0 & 0 & .5 & .25 & .03 \\
\hline 5 & 75.2 & 0 & 12 & 5 & 0 & 7 & 0 & 0 & 0 & .5 & .25 & .03 \\
\hline 6 & 69.2 & 0 & 12 & 5 & 0 & 13 & 0 & 0 & 0 & .5 & .25 & .03 \\
\hline 7 & 69.2 & 0 & 18 & 5 & 0 & 7 & 0 & 0 & 0 & .5 & .25 & .03 \\
\hline 8 & 63.2 & 0 & 18 & 5 & 0 & 13 & 0 & 0 & 0 & .5 & .25 & .03 \\
\hline 9 & 74.2 & 0 & 15 & 0 & 0 & 10 & 0 & 0 & 0 & .5 & .25 & .03 \\
\hline 10 & 69.2 & 0 & 15 & 5 & 0 & 10 & 0 & 0 & 0 & .5 & .25 & .03 \\
\hline 11 & 74.7 & 0 & 12 & 2.5 & 0 & 10 & 0 & 0 & 0 & .5 & .25 & .03 \\
\hline 12 & 68.7 & 0 & 18 & 2.5 & 0 & 10 & 0 & 0 & 0 & .5 & .25 & .03 \\
\hline 13 & 74.7 & 0 & 15 & 2.5 & 0 & 7 & 0 & 0 & 0 & .5 & .25 & .03 \\
\hline 14 & 68.7 & 0 & 15 & 2.5 & 0 & 13 & 0 & 0 & 0 & .5 & .25 & .03 \\
\hline 15 & 71.7 & 0 & 15 & 2.5 & 0 & 10 & 0 & 0 & 0 & .5 & .25 & .03 \\
\hline 16 & 65.7 & 0 & 21 & 2.5 & 0 & 10 & 0 & 0 & 0 & .5 & .25 & .03 \\
\hline 17 & 77.7 & 0 & 15 & 2.5 & 0 & 4 & 0 & 0 & 0 & .5 & .25 & .03 \\
\hline 18 & 65.7 & 0 & 15 & 2.5 & 0 & 16 & 0 & 0 & 0 & .5 & .25 & .03 \\
\hline 19 & 81.7 & 0 & 15 & 2.5 & 0 & 0 & 0 & 0 & 0 & .5 & .25 & .03 \\
\hline 20 & 74.7 & 0 & 15 & 2.5 & 0 & 0 & 3 & 1 & 3 & .5 & .25 & .03 \\
\hline 21 & 73.4 & 0 & 15 & 2.5 & 0 & 0 & 2.5 & 0.8 & 5 & .5 & .25 & .03 \\
\hline 22 & 68.4 & 0 & 15 & 2.5 & 0 & 10 & 2.5 & 0.8 & 0 & .5 & .25 & .03 \\
\hline 23 & 66.0 & 0 & 15 & 2.5 & 0 & 10 & 2 & 0.7 & 3 & .5 & .25 & .03 \\
\hline
\end{tabular}


All experimental heats were made by vacuum induction melting in $\mathrm{MgO}$ crucibles under partial vacuum back-filled with 0.5 atm of argon gas; rectangular casts of $2 \mathrm{~cm} \times 5$ $\mathrm{cm} \times 15 \mathrm{~cm}$ were produced. The casts were homogenization-heat treated at $1200^{\circ} \mathrm{C}$ for 4 hrs under an argon gas atmosphere; then they were hot-rolled at $1200^{\circ} \mathrm{C}$ into $0.6 \mathrm{~cm}$ thick plates. Blanks cut from the plates were heat-treated as follows:

Alloys 1-18: $\quad 1000^{\circ} \mathrm{C} / 4 \mathrm{hrs} /$ Air Cooling

Alloys $20-23: \quad 1000^{\circ} \mathrm{C} / 4 \mathrm{hrs}+850^{\circ} \mathrm{C} / 20 \mathrm{hrs}+700^{\circ} \mathrm{C} / 20 \mathrm{hrs}+650^{\circ} \mathrm{C} / 20 \mathrm{hrs}$

As a result, the Vicker's diamond pyramid micro-hardness (DPH) of the precipitation-hardened alloys, Nos. 20 to 23, ranged from 370 to 440 whereas that of a solid-solution alloy, No. 15, was 302 .

A check on the chemical composition was made on four selected alloys, Nos. 13, 15, 22 and 23. The actual contents of the major alloying elements, $\mathrm{Cr}, \mathrm{Mo}$ and Fe, and some of the minor alloying elements, $\mathrm{Al}, \mathrm{Mn}$ and $\mathrm{Si}$ were within $10 \%$ of the aimed values. Titanium showed a positive variation of up to $14 \%$ from the aimed value; carbon showed a negative variation as large as $60 \%$ from the aimed value. According to Eq. (2) these variations of the actual composition from the nominal composition might result in deviations, ranging from $-0.1322 \times 10^{-6} /{ }^{\circ} \mathrm{C}$ to $+0.1134 \times 10^{-6} /{ }^{\circ} \mathrm{C}$ from the predicted $\alpha$ of the reference composition for precipitation-hardened alloys, $\mathrm{Ni}-15 \mathrm{Cr}-2.5 \mathrm{Mo}-10 \mathrm{Fe}-2.5 \mathrm{Ti}-1.0 \mathrm{Al}-0.5 \mathrm{Mn}-0.25 \mathrm{Si}-0.03 \mathrm{C}$. The magnitude of the deviation is below $1 \%$ of the $\alpha$ of the reference composition. No corrections were made to account for this aberration because of its insignificant magnitude and of the limited amount of data on the chemical analysis.

The microstructure of solid-solution alloys showed equiaxed grains whose size ranged from 30 to $100 \mu \mathrm{m}$. Some alloys showed "ghost" boundaries formed by the segregation of inclusions. The grain size of the precipitation-hardened alloys was smaller than that of the solid-solution alloys. The precipitation-hardened alloys showed dendritic segregation of inclusions in the hot rolled condition, which disappeared after solution-heat treatment. Alloys of complex compositions, e.g., $\mathrm{Ni}-15 \mathrm{Cr}-2.5 \mathrm{Mo}-$ 10Fe-2Ti-0.7 Al-3Nb-0.5Mn-0.25Si-0.03C (No. 23), often showed secondary phases on the grain boundaries. The secondary phase in this particular composition was identified as $\delta$ phase which is often found in commercial alloys such as Inconel 718 and Inconel 706 alloys. The $\delta$ phase consists of nickel and niobium $\left(\mathrm{Ni}_{3} \mathrm{Nb}\right)$ and has an orthorombic structure. When properly distributed, this phase is known to be beneficial to the high temperature notch ductility, as documented elsewhere ${ }^{6}$.

The major phases responsible for strengthening the precipitation-hardened alloys are $\gamma^{\prime}\left(\mathrm{Ll}_{2}\right)$ or $\gamma^{\prime \prime}\left(\mathrm{DO}_{22}\right)$, or a mixture of the two with their relative amount determined by the ratio of $\mathrm{Nb} /(\mathrm{Ti}+\mathrm{Al})$ in the alloy composition. The presence of these phases was confirmed by electron microscopy.

Specimens for the thermal expansion measurement were made from heat-treated blanks, the axes of the specimens being parallel to the rolling direction. The specimens were $5 \mathrm{~cm}$ long and $0.6 \mathrm{~cm} \times 0.6 \mathrm{~cm}$ in cross section. The thermal expansion was measured with a dilatometer with a LVDT (Linear Variable Differential Transformer) system. The average thermal expansion coefficient, $\alpha$, corresponding to each temperature range was calculated by dividing the amount of total expansion for the 
temperature range by the temperature difference. The estimate of the standard error in this measurement technique was estimated to be approximately $3 \%$ of the measured value.

The thermal expansion of the experimental alloys was measured from room temperature to $760^{\circ} \mathrm{C}$. The thermal expansion curves for the solid solution alloys were similar to the ones for the precipitation-hardened alloys. The results of the measurements are summarized in Table III; the effects of the major alloying elements, $\mathrm{Fe}, \mathrm{Cr}$ and $\mathrm{Mo}$, are illustrated in Fig. 1. The figure was generated by calculating $\alpha$ of the imaginary compositions in which the content of the major alloying elements was varied from the reference composition for solid-solution alloys, $\mathrm{Ni}-15 \mathrm{Cr}-2.5 \mathrm{Mo}-$ $10 \mathrm{Fe}-0.5 \mathrm{Mn}-0.25 \mathrm{Si}-0.03 \mathrm{C}$. As shown in the figure, the experimental results demonstrate the general trend of the alloying elements well. However, the absolute values of $\alpha$ 's showed deviations from the predicted values which, in some alloys, were larger than the standard error of the regression model. Also, the deviations showed a positive bias from the predicted values: 22 alloys showed $\alpha$ greater than the predicted values whereas only one alloy showed the opposite.

Table III.

Mean thermal expansion coefficients, $\alpha_{538}{ }^{\circ} \mathrm{C}$, of the experimental alloys. Unit: $10^{-6} /{ }^{\circ} \mathrm{C}$

\begin{tabular}{ccccc} 
Alloy No. & meas. $\bar{\alpha}$ & pred. & Deviation & \% Deviation \\
\cline { 2 - 3 } 1 & 15.41 & 14.85 & +0.56 & +3.8 \\
2 & 15.66 & 15.07 & +0.59 & +3.9 \\
3 & 15.62 & 14.92 & +0.70 & +4.7 \\
4 & 15.93 & 15.14 & +0.79 & +5.2 \\
5 & 14.74 & 14.42 & +0.32 & +2.2 \\
6 & 14.62 & 14.67 & -0.05 & -0.3 \\
7 & 14.65 & 14.49 & +0.16 & +1.1 \\
8 & 15.23 & 14.74 & +0.49 & +3.3 \\
9 & 15.23 & 14.99 & +0.24 & +1.7 \\
10 & 15.01 & 14.58 & +0.43 & +2.9 \\
11 & 15.07 & 14.74 & +0.33 & +2.2 \\
12 & 15.55 & 14.83 & +0.72 & +4.9 \\
13 & 15.55 & 14.67 & +0.88 & +3.3 \\
14 & 15.39 & 14.90 & +0.49 & +3.6 \\
15 & 15.34 & 14.80 & +0.54 & +6.3 \\
16 & 15.79 & 14.85 & +0.94 & +3.7 \\
17 & 15.10 & 14.56 & +0.54 & +3.3 \\
18 & 15.53 & 15.03 & +0.50 & +5.8 \\
19 & 15.28 & 14.44 & +0.84 & +5.3 \\
20 & 14.71 & 13.97 & +0.74 & +4.1 \\
21 & 14.58 & 14.00 & +0.58 & +1.4 \\
22 & 14.65 & 14.45 & +0.20 & +2.1 \\
23 & 14.78 & 14.47 & +0.31 &
\end{tabular}




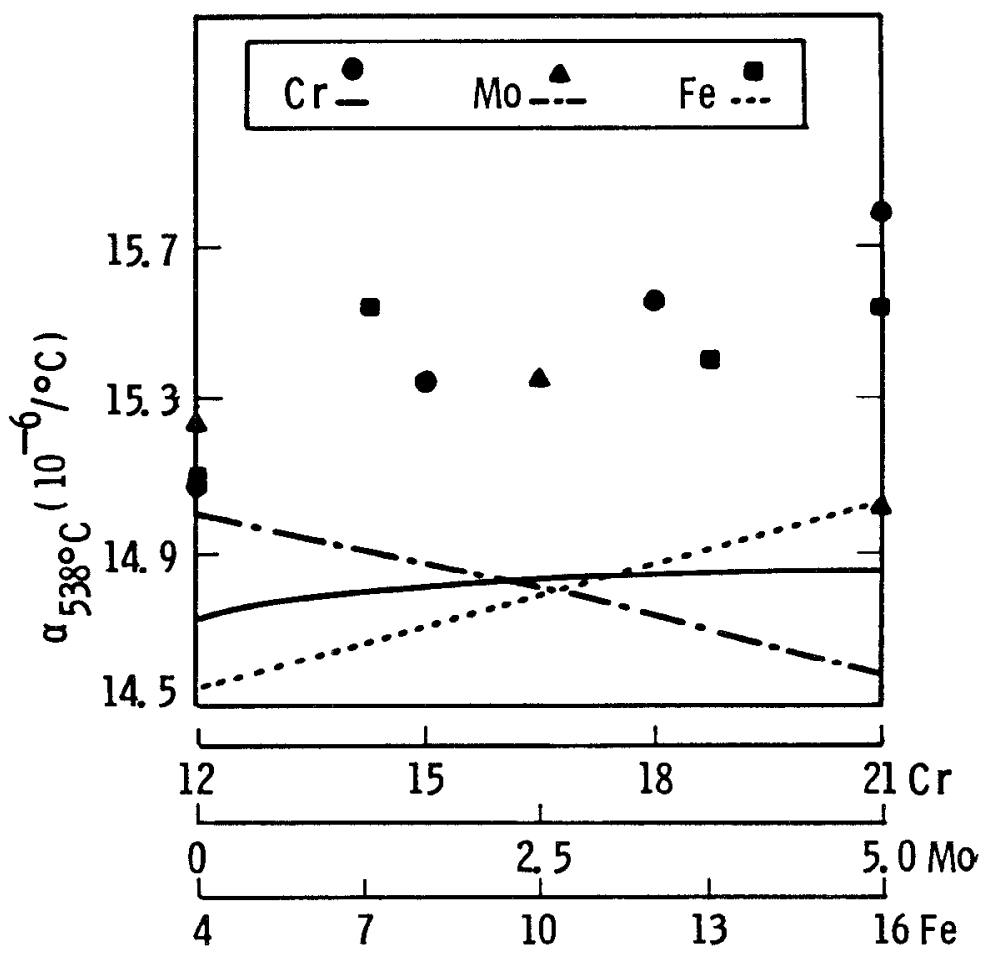

Fig. 1 The effects of alloying elements (wt.\%) on the mean thermal expansion coefficients, $\alpha_{538^{\circ} \mathrm{C}}$, of the experimental alloys.

Reference comp.: $\mathrm{Ni}-15 \mathrm{Cr}$ 2.5Mo-10Fe-0.5 Mn-0.03C

Lines: Predictions

Points: Observations

\section{SCC-Resistance of Experimental Alloys}

The SCC-tests were conducted in two environments: (1) $42 \% \mathrm{MgCl}_{2}$ solution boiling at $150^{\circ} \mathrm{C}$, and (2) $10 \% \mathrm{NaOH}$ solution at $316^{\circ} \mathrm{C}$, pressurized to $10.3 \mathrm{MPa}$. Specimens were made from strips of $2.5 \mathrm{~mm} \times 12.7 \mathrm{~mm} \times 89 \mathrm{~mm}$ in size, which were bent into U-shape and clamped with nickel-alloy bolts. The U-bend strips were submerged in the solutions and periodically examined for crack initiations (approximately $100 \mu \mathrm{m}$ deep) with a binocular microscope.

Most of the solid-solution alloys showed a good SCC-resistance in the $\mathrm{MgCl}_{2}$ solution as well as in the $\mathrm{NaOH}$ solution. In the $\mathrm{MgCl}_{2}$ solution, all the solid solution alloys except Nos. 14 and 17 endured 5000 hrs. Alloys Nos. 14 and 17 developed cracks during the period of 2300-5000 hrs exposure. On the $\mathrm{NaOH}$ solution, all the solid solution alloys except Nos. 5, 6, 7 and 8 showed no crack after 2000 hrs, the maximum exposure time. Most of the specimens of Alloys Nos. 5, 6, 7 and 8 cracked during the period of 700-2000 hrs exposure.

The precipitation-hardened alloys showed a relatively high SCC-susceptibility compared to the solid-solution alloys. Particularly, the alloys containing relatively high quantities of the hardners, $\mathrm{Ti}, \mathrm{Al}$ and $\mathrm{Nb}$, Nos. 20 and 21, were brittle, and the specimens broke during bending into U-shape. The alloys with lower amount of the hardners, Nos. 22 and 23 , showed no cracking after 5000 hrs exposure in the $\mathrm{MgCl}_{2}$ solution; however, in the $\mathrm{NaOH}$ solution, they cracked within 70 hrs. A few reference specimens made from commercial Inconel X-750 alloy also cracked within $70 \mathrm{hrs}$ in the 
$\mathrm{NaOH}$ solution.

\section{Discussion}

The positive bias of the measured $\alpha$ values from the predictions of the regression model may be due to the measurement technique. The technique used in the present study was estimated to have a standard error of $3 \%$ of the absolute measured value; however, the accuracy is better when the measurement is repeated on an identical specimen or on a series of identically produced materials with only a minor difference in compositions. Nevertheless, a systematic bias may be introduced from various sources such as the thermocouple or the transformer. To check the variability, an independent measurement using a technique called "differential thermal expansion measurement" was performed on two newly made alloys: Ni-15Cr-7Mo-10Fe-0.5Mn-0.25Si and $\mathrm{Ni}-15 \mathrm{Cr}-7 \mathrm{Mo}-10 \mathrm{Fe}-2.5 \mathrm{Ti}-0.7 \mathrm{Al}-0.5 \mathrm{Mn}-0.25 \mathrm{Si}$. This technique uses an NBS reference specimen (single crystal sapphire) in parallel with the object specimen. The standard error for this technique is typically $1 \%$ of the measured value. The results obtained by the "differential thermal expansion measurement" were consistently lower than those obtained by the technique used in the present work. Therefore, it is possible that the deviations shown in Table III were due to a systematic bias of the measurement technique, and that the actual agreement between the measurement results and the regression model prediction might have been better. A refined model with this consideration taken into account will be published elsewhere ${ }^{7}$.

Morrow, Sponseller and Semchysen ${ }^{3}$ reported that the thermal expansion coefficient of the $\gamma$ ' phase is lower than that of the $\gamma$ solid solution phase. These authors measured the thermal expansion of experimental $\mathrm{Ni}-\mathrm{Cr}$ alloys with varying amounts of Mo, Al and Ti. Using the $\gamma^{\prime}$ volume fraction data of Loomis, et al. ${ }^{8}$ and Biss and Sponseller $^{9}$ on the same alloys they calculated the separate expansion coefficients of the $\gamma$ and $\gamma^{\prime}$ phases by extrapolation to 0 and 1.0 volume fraction $\gamma^{\prime}$, respectively. A $\alpha_{\gamma}$, value of $\alpha_{800^{\circ} \mathrm{C}}=14.72 \times 10^{-6} /{ }^{\circ} \mathrm{C}$ was obtained for Mo-free alloys and a value of $\alpha_{800}{ }^{\circ} \mathrm{C}=14.39$ $\times 10^{-6} /{ }^{\circ} \mathrm{C}$ was obtained for the 8 wt. pct. Mo alloys. Morrow, et al. attributed the lower value of $\alpha_{\gamma}$, as being due to the presence of 6.5 pct. Mo in the $\gamma$ ' phase. These values were favorably compared to the data of Stoeckinger and Newmann ${ }^{10}$ who reported $\alpha_{800^{\circ} \mathrm{C}}=15 \times 10^{-6} /{ }^{\circ} \mathrm{C}$ for pure $\mathrm{Ni}_{3} \mathrm{Al}$. Morrow, et al. found that Mo decreased the thermal expansion coefficients of the alloys for all $\mathrm{Al}$ and Ti levels studied and for all temperatures below the solution temperature of $\gamma^{\prime}$. Increasing $\mathrm{Al}$ and Ti contents also lowered the $\alpha_{\text {alloy }}$ at temperatures below the $\gamma^{\prime}$ solution temperature. They also calculated the specific effect of Mo on the $\alpha_{800}{ }^{\circ} \mathrm{C}$ for the solid solution phase to be -0.16 $\mathrm{x} 10^{-6} /{ }^{\circ} \mathrm{C}$ per wt. pct. Mo. Considering that this value is for the $\gamma$ phase only where $\alpha_{\gamma}>\alpha_{\text {alloy }}>\alpha_{\gamma}$, and for a higher temperature level where $\alpha_{800^{\circ} \mathrm{C}}>\alpha_{538^{\circ} \mathrm{C}}$, it compares quite reasonably with the coefficient of $-0.1012 \times 10^{-6} /{ }^{\circ} \mathrm{C}$ shown in Eq. (2).

In a Soviet study by Ryabtsev, Kornilov and Pryakhina ${ }^{11}$, thermal expansion was one of the physicochemical properties investigated for a series of laboratory nickel-base alloys containing from two to eight elements in the series: $\mathrm{Ni}(\mathrm{Bal}$.), $\mathrm{Cr}$ (10 wt. \%), $\mathrm{Ti}(2$ wt. \%), W (6 wt. \%), Mo (3 wt. \%), Nb (2 wt. \%), Co (5 wt. \%) and Al (0 to 10 wt. \%). These authors found a very strong effect of increasing $\mathrm{Al}$ content on decreasing the 
thermal expansion of their alloys. For their most complex alloy containing all eight of the above composition elements, they found $\Delta \alpha_{800^{\circ} \mathrm{C}}$ of $2.0 \times 10^{-6} /{ }^{\circ} \mathrm{C}$ with an increase from 2 to 6 wt. pct. Al. This calculates to a $-0.5 \times 10^{-6} /{ }^{\circ} \mathrm{C}$ per wt. pct. Al effect which is much larger than the $-0.0214 \times 10^{-6} /{ }^{\circ} \mathrm{C}$ per wt. pet. Al effect shown in Table I. Since the thermal expansion data for the other alloys in their investigation was not reported, one is not able to calculate whether the $\mathrm{Al}$ effect was consistently so large. The Soviet authors also claimed that the thermal expansion coefficient of the nickel-base alloys would decrease as the number of alloying elements increased, due to the resulting decrease in the root-mean-square displacement of atoms from the equilibrium position. This generalization is bound to have many exceptions because of the differences in the relative intensity of the alloying elements as shown in Eq. (2).

\section{Conclusions}

(1). A regression model was developed to predict the average thermal expansion coefficients $(\alpha)$ of nonmagnetic Ni-base alloys and austenitic steels. Among the major alloying elements for solid-solution hardened alloys, $\mathrm{C}$ and Mo were found to have strong effects of decreasing $\alpha$; $\mathrm{Mn}$ and Fe the opposite. The precipitation-hardening elements, $\mathrm{Ti}, \mathrm{Al}, \mathrm{Nb}$ and $\mathrm{Ta}$, were found to decrease $\alpha$.

(2). The experimental measurement of $\alpha_{538}{ }^{\circ} \mathrm{C}$ 's of a group of Ni-base alloys confirmed the general trend of the major alloying elements as predicted by the regression model. However, the measured $\alpha$ 's showed deviations with a positive bias, which was attributed to the measurement technique.

(3) The experimental solid solution alloys showed good SCC-resistance in a boiling $\mathrm{MgCl}_{2}$ solution and in a pressurized, hot $\mathrm{NaOH}$ solution. The precipitation-hardened alloys showed comparatively low SCC-resistance, particularly in the $\mathrm{NaOH}$ solution.

\section{References}

(1). D. R. Muzyka and D. K. Schlosser, "Controlled Expansion Alloy," U. S. Patent No. 4,006,0011 (1977).

(2). D. R. Muzyka, C. R. Whitney, and D. K. Schlosser, "Physical Metallurgy and Properties of a New Controlled-Expansion Superalloy," J. of Metals, 27(7) (1975) pp 11-15.

(3). H. Morrow III, D. L. Sponseller, and M. Semchyshen, "The Effects of Molybdenum and Aluminum on the Thermal Expansion Coefficients of Nickel-Base Alloys," Met. Trans., 6A (1975) pp. 477-485.

(4). C. D. Lundin, "Dissimilar Metal Welds-Transition Joints Literature Review," The Welding Journal Research Suppl., (2)(1972) 58S-63S.

(5). C. C. Li, R. Viswanathan, and R. H. Ryder, "The Microstructure and Remaining Life of Dissimilar Metal Weldments after Service in Fossil-Fired Boilers, " pp. 315-325 in AIME International Conference on Advances in Life Prediction Methods, Albany, New York, D. A. Woodford and J. R. Whitehead, ed.; ASME, New York, 1983.

(6). R. F. Decker and C. T. Sims: "The Metallurgy of Nickel-Base Alloys," pp 
33-77 in The Superalloys, C. T. Sims and W. C. Hazel, ed.; John Wiley \& Sons, 1972.

(7). J. M. Wells, S. K. Hwang and F. C. Hull: "Compositional Effects on The Thermal Expansion of Iron and Nickel Base Superalloys, " presented for publication to the First USA-Brasil Superalloy Conference, Araxa, Brasil, April 1984.

(8). W. R. Loomis, J. W. Freeman and D. L. Sponseller, "The Influence of Molybdenum on the $\gamma^{\prime}$ Phase in Experimental Nickel-Base Superalloys, " Met. Trans., 3A(1972) pp. 980-1000.

(9). V. Biss and D. L. Sponseller, 'The Effect of Molybdenum on $\gamma$ ' Coarsening and on Elevated-Temperature Hardness in Some Experimental Nickel-Base Superalloys, " Met. Trans., 4A(1973) pp. 1953-1960.

(10). G. R. Stoeckinger and J. P. Neumann, "Determination of the Order in the Intermetallic Phase $\mathrm{Ni}_{3} \mathrm{Al}$ as a Function of Temperature," J. of Applied Crystallography, 3(1) (1970) pp. 32-38.

(11). L. A. Ryabtsev, I. I. Kornilov and L. J. Pryakhina, "Heat Resistance and Physicochemical Properties of Complex Nickel-Base Alloys, " pp. 155-160 in Structure and Properties of Heat-Resistance Metals and Alloys, (English Translations), M. V. Pridantsev, ed.; 1970. 